\title{
Application of digital image correlation system for analysis of local plastic instabilities of perforated thin-walled bars
}

\author{
Andrzej Piotrowski ${ }^{1}$, Marcin Gajewski ${ }^{1,}{ }^{*}$, and Cezary Ajdukiewicz ${ }^{1}$ \\ ${ }^{1}$ Warsaw University of Technology, Civil Engineering Department, Lech Kaczyński 16 street, 00-637 \\ Warsaw, Poland
}

\begin{abstract}
In the presented paper the local instabilities occurring in compression test of perforated thin-walled bars of low slenderness are observed using digital image correlation system ARAMIS. The tested samples slenderness is so low, that from theoretical point of view we are dealing with compression tests of some perforated shells. The samples are made from typical low carbon steel, which has to be treated as elastoplastic material. Because of that, the final geometry of the sample (after unloading) is also analysed giving a good data for calibration of the theory of elasto-plasticity for large deformations. In analysed cases the total strain values are not exceptionally large, while local rotation (and permanent deformations) have significant values.
\end{abstract}

\section{Introduction}

The paper deals with analysis of the local plastic instabilities of perforated thin-walled bars [1] of a low slenderness value ( $\lambda$ ranging from 1 to 11) in compression tests. From theoretical point of view, bars of such low slenderness have to be treated as compressed shells. In such case the final configuration shape (after full unloading) depends not only on elasticity properties. The basic material of the samples being mild steel in general is an isotropic one, but with clearly distinct plastic behaviour after crossing the Huber-Mises yield condition which was used for modelling in the papers [2,3]. The fact of strong plastic material behaviour determine the observed failure modes, which in the analysed slenderness range are of the local nature rather.

The deformation development (including local instabilities of walls) are observed using digital image correlation (DIC) system ARAMIS [4-7] with two cameras registering the movement of points located in observation range through distinct grey level (determined for each facet) obtained on the basis of random pattern (black pattern on white background). Thanks to DIC system the deformation components may be registered in some observational range [8-13], being full side wall of the bar (for lower slenderness) or a part of the side wall in case of higher slenderness value.

\footnotetext{
* Corresponding author: m.gajewski@il.pw.edu.pl
} 


\section{Elements for testing}

Elements chosen for testing are a typical storage system columns, which cross-section is formed in cold-bending process from perforated thin blank. Geometry of the tested elements is shown in Figure 1.

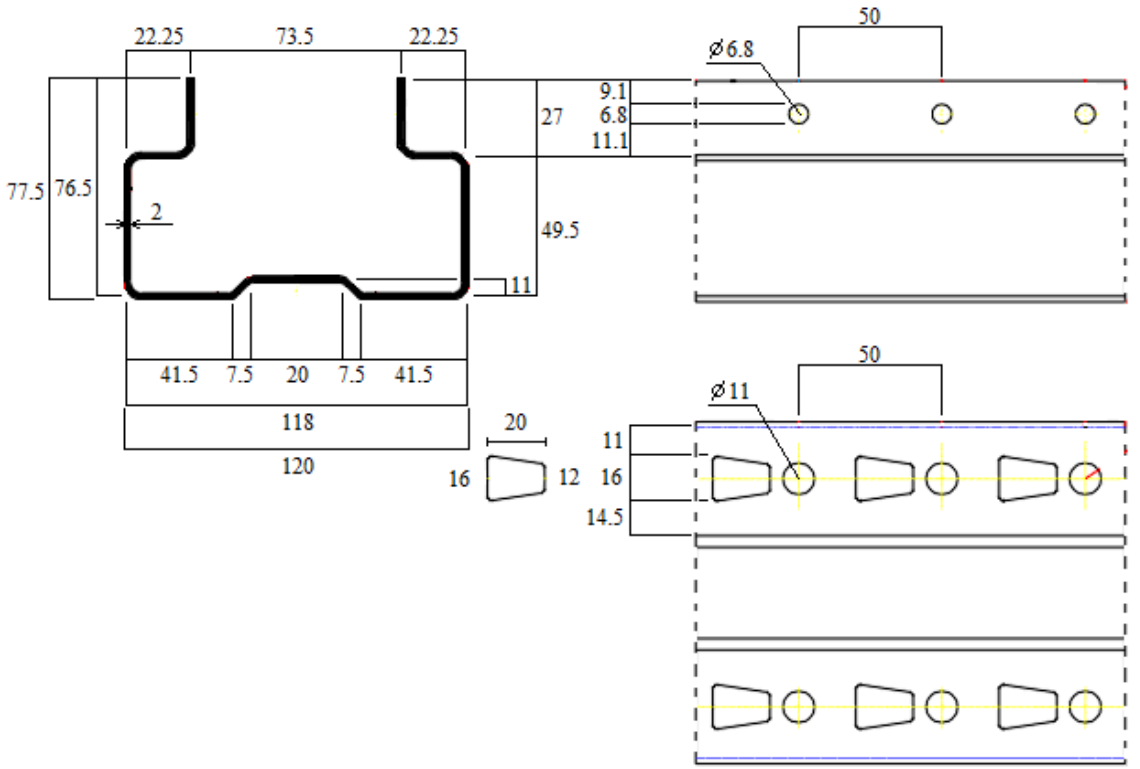

Fig. 1. Dimensions of a cross-section of tested elements altogether with locations and dimensions of perforations [3].

The material of the sample is a mild steel, which can be treated as elasto-plastic material [14]. The uniaxial tension test results for this material are presented in Figure 2. Based on these results, the Young modulus $\mathrm{E}=230 \mathrm{GPa}$, proportionality limit $\mathrm{R}_{\mathrm{H}}=383.2$ $\mathrm{MPa}$ and plasticity limit $\mathrm{R}_{\mathrm{e}}=453.5 \mathrm{MPa}$ are determined.

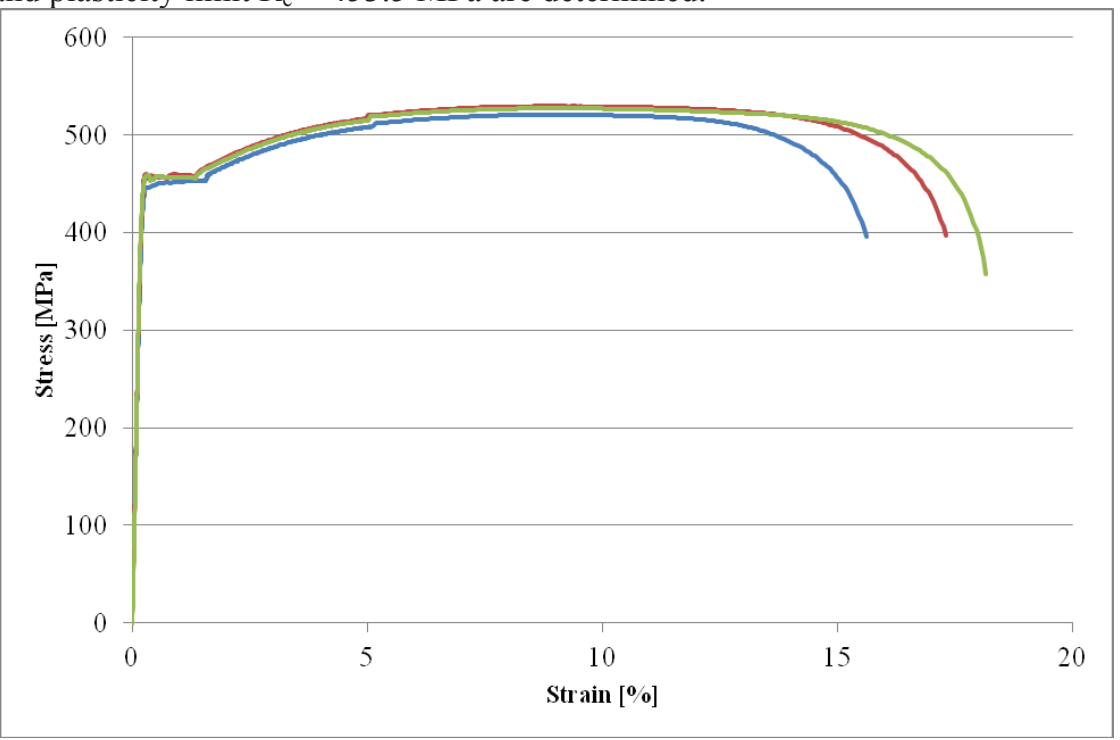

Fig. 2. Uniaxial tension test result of sample's material. 


\section{Testing methodology}

Tested elements were compressed with the Instron 8802 universal testing machine. Fixtures for sample's mounting were carved to ensure proper realization of boundary conditions, see Figure 3, which was sufficient for short elements, but didn't work when applying big displacements to the longest tested elements, in which case the angles of the bar's ends changed near the end of the test (although it still worked during the most important part of the test, i.e. during the buckling). Lengths of the tested elements ranged from 50 to $500 \mathrm{~mm}$ (slenderness from 1 to 11). Fixture groove's depth is equal to $5 \mathrm{~mm}$.

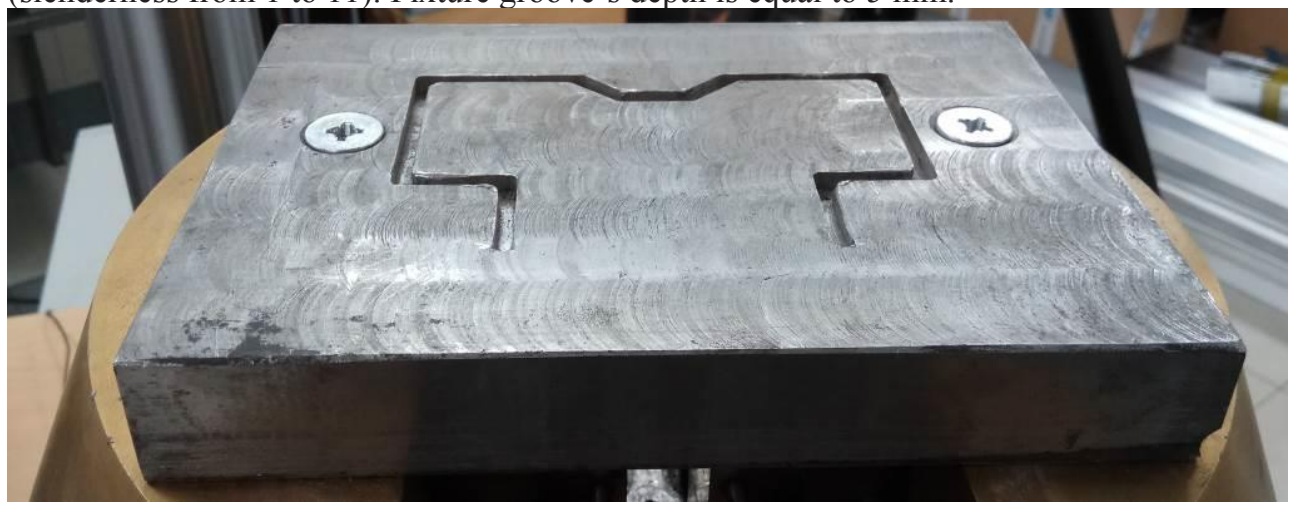

Fig. 3. Fixture for mounting the sample in compression test.

Displacement speed was constant during the test and selected in accordance to the length of the tested element, so that the average strain would be equal to 4 percent per minute (static test). End of the test condition was displacement producing the average strain equal to $10 \%$.

The whole process was recorded with the testing machine and ARAMIS digital image correlation system [4]. Additionally, selected permanent displacements were measured manually after the test.

\section{Test results and analysis}

The equilibrium paths obtained as a result of the test are presented in Figure 4. As it can be seen, the paths are shown without any processing, especially without deleting the beginning parts, when the tested elements are "fitting" to the fixtures.

Regarding part of the graph resulting from elastic material behaviour, it can be noted, that even though all elements were cut from the same column, the compression stiffness is smaller for shorter bars. Reasons are currently unknown, but it may be due to scale effect, the heat created during cutting, or not ideal realization of boundary conditions (not perfect fitting of the sample and compression fixture).

Aside from the shortest element, which couldn't be destroyed using this testing machine, all elements were destroyed similarly, through plastic buckling. The shorter the element, the milder the top of the graph and bigger critical force, although the critical forceslenderness curve cannot be created yet, because of too small number of tests (see Table 1). Second shortest element buckled in an unusual way (very sudden change of geometry after about 7 seconds under maximal possible force), probably because of testing machine limits, but its buckling form was similar to other tested elements.

In three longest specimens some irregularities can be seen for large strains - it is caused by the ends of the bars going out of the grooves in compressing fixtures. 


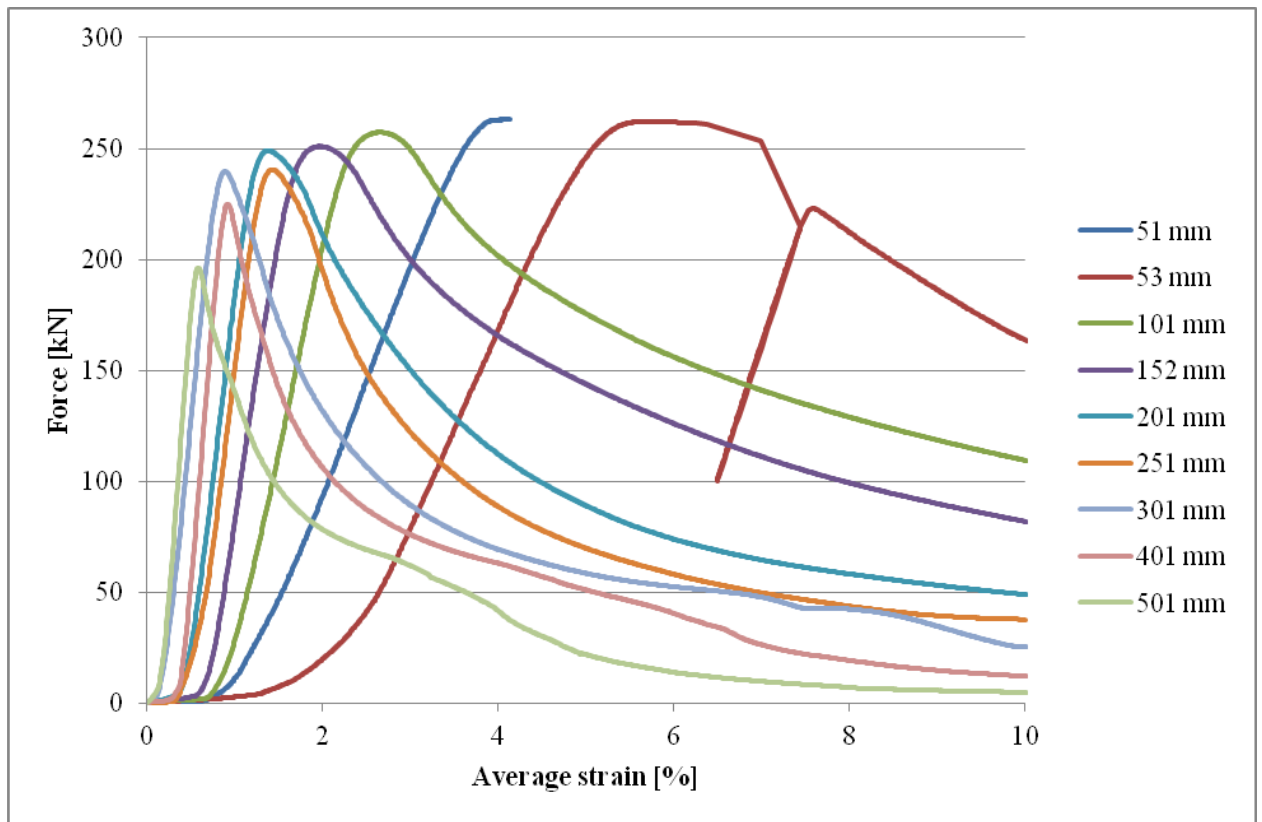

Fig. 4. Equilibrium paths for elements of different lengths.

Table 1. Critical force in the function of slenderness (value for zero slenderness was calculated as force corresponding to plasticity limit [1,3]).

\begin{tabular}{|c|c|c|c|c|c|c|c|c|c|}
\hline$\lambda[-]$ & 0 & 1.122 & 2.139 & 3.219 & 4.257 & 5.315 & 6.374 & 8.492 & 10.61 \\
\hline $\mathrm{P}_{\text {crit }}[\mathrm{kN}]$ & 269.4 & 262.1 & 257.3 & 251.0 & 249.1 & 240.5 & 239.8 & 225.0 & 196.3 \\
\hline
\end{tabular}

Although buckling forms were similar for different lengths, they were not identical, and some changes can be seen for every change in size. Critical forces for two longest bars are smaller than the force corresponding to proportionality limit, but results obtained from DIC system show, that all of the elements buckled, when strains on their surface were about ten times larger than the ones corresponding to the plasticity limit.

Destroyed specimens are shown in Figure 6 and results of post-testing measurements are given in Table 2. The measured dimensions given in the Table 2 are shown in Figure 5.

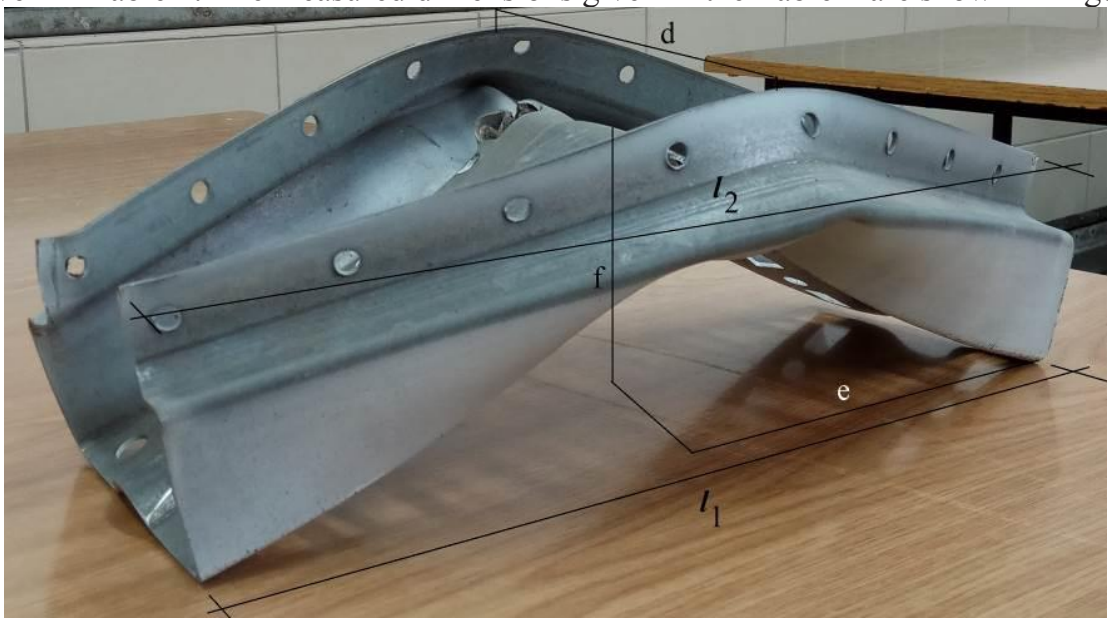

Fig. 5. Permanent deformation measurements. 
Table 2. Permanent deformation measurements.

\begin{tabular}{|c|c|c|c|c|c|}
\hline $\boldsymbol{l} \boldsymbol{0} / \boldsymbol{\Lambda}$ & $\boldsymbol{l}_{\mathbf{1}}[\mathbf{m m}]$ & $\boldsymbol{l}_{\boldsymbol{}}[\mathbf{m m}]$ & $\mathbf{d}[\mathbf{m m}]$ & $\mathbf{e}[\mathbf{m m}]$ & $\mathbf{f}[\mathbf{m m}]$ \\
\hline $53 / 0.122$ & 49.9 & 49.8 & 82.0 & 25.8 & 15.1 \\
\hline $101 / 2.139$ & 92.8 & 91.9 & $67.5^{*}$ & 38.3 & 26.5 \\
\hline $152 / 3.219$ & 137 & 140 & 109 & 79.0 & 35.9 \\
\hline $201 / 4.257$ & 179 & 181 & 151 & 82.9 & 48.5 \\
\hline $251 / 5.315$ & 226 & 226 & 184 & 121 & 55.8 \\
\hline $301 / 6.374$ & 260 & 277 & 171 & 118 & 73.9 \\
\hline $401 / 8.492$ & 347 & 372 & 147 & 187 & 103 \\
\hline $501 / 10.61$ & 427 & 466 & $180^{* *}$ & 217 & 138 \\
\hline
\end{tabular}

(*) Both sides went into the same direction. $(* *)$ The material has been torn in the measurement place.

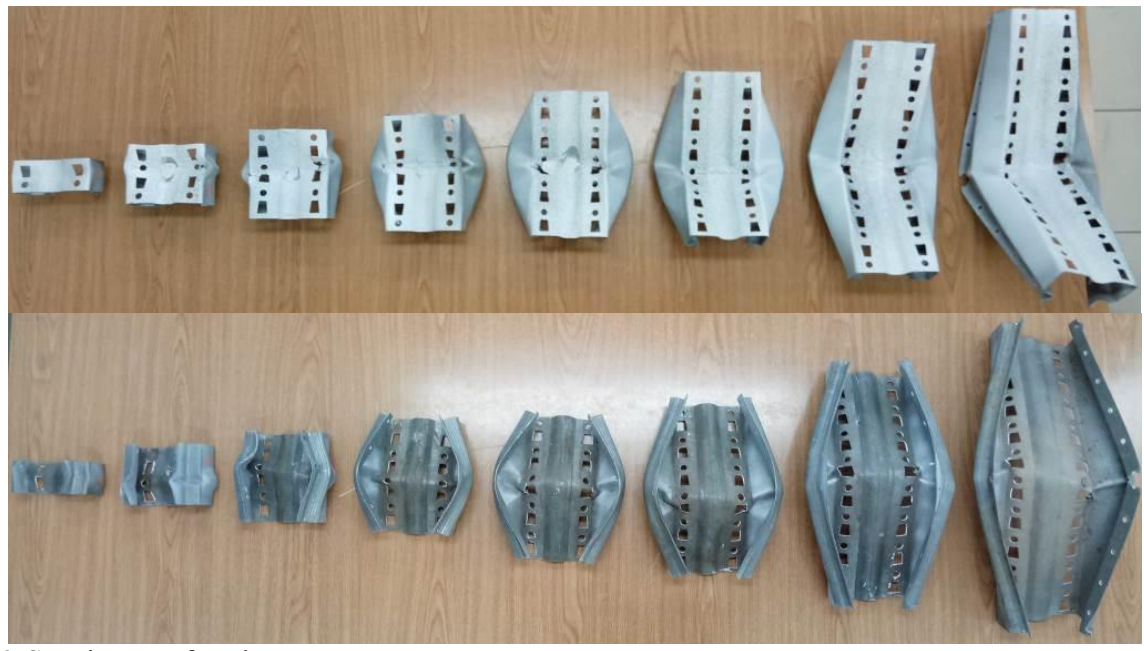

Fig. 6. Specimens after the test.

Huber-Mises strain fields obtained from the DIC system are presented in Table 3. Beige background of the cell means, that the photograph was taken under the maximal force.

In all of the tested specimens strains greater than the average appeared in some places, when the element was buckling. In shorter elements this effect begins before buckling and in longer during or after it. In all specimens aside from the shortest one big strains areas start from the corners near the longer bases of the trapezoidal perforations, and later connect with the corners near the shorter bases of the neighbouring ones. In the shortest element strain concentration regions develop from the circular perforation, and later connects with the trapezoidal one. After some time strains near one of the perforations become bigger than near others, and bar is bended in that place. In general, elements buckling forms are symmetrical, but since the left and right areas of big strains are not connected in the moment of buckling, sometimes the specimens become little slanted. 
Table 3. Equivalent Huber-Mises strain fields.

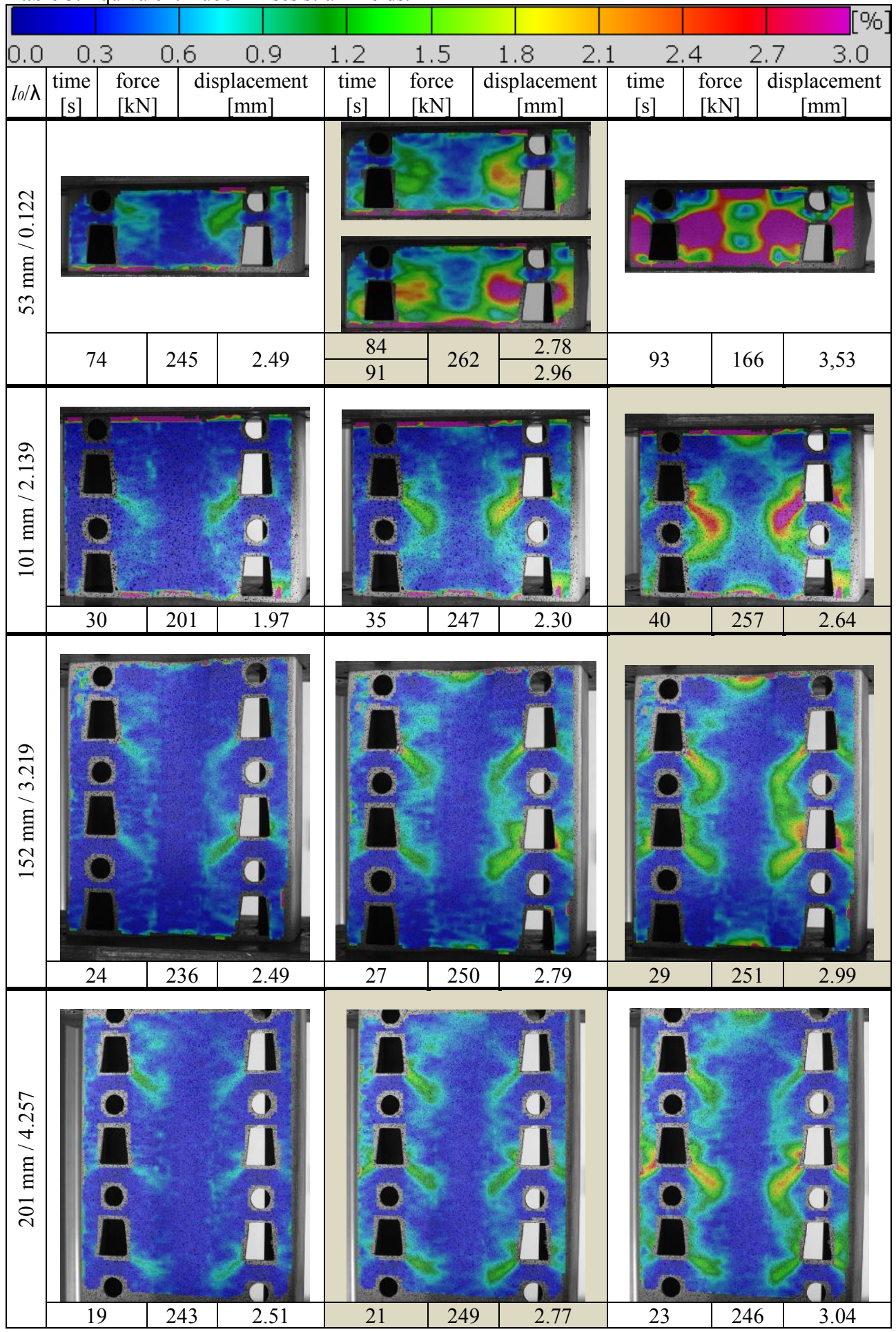




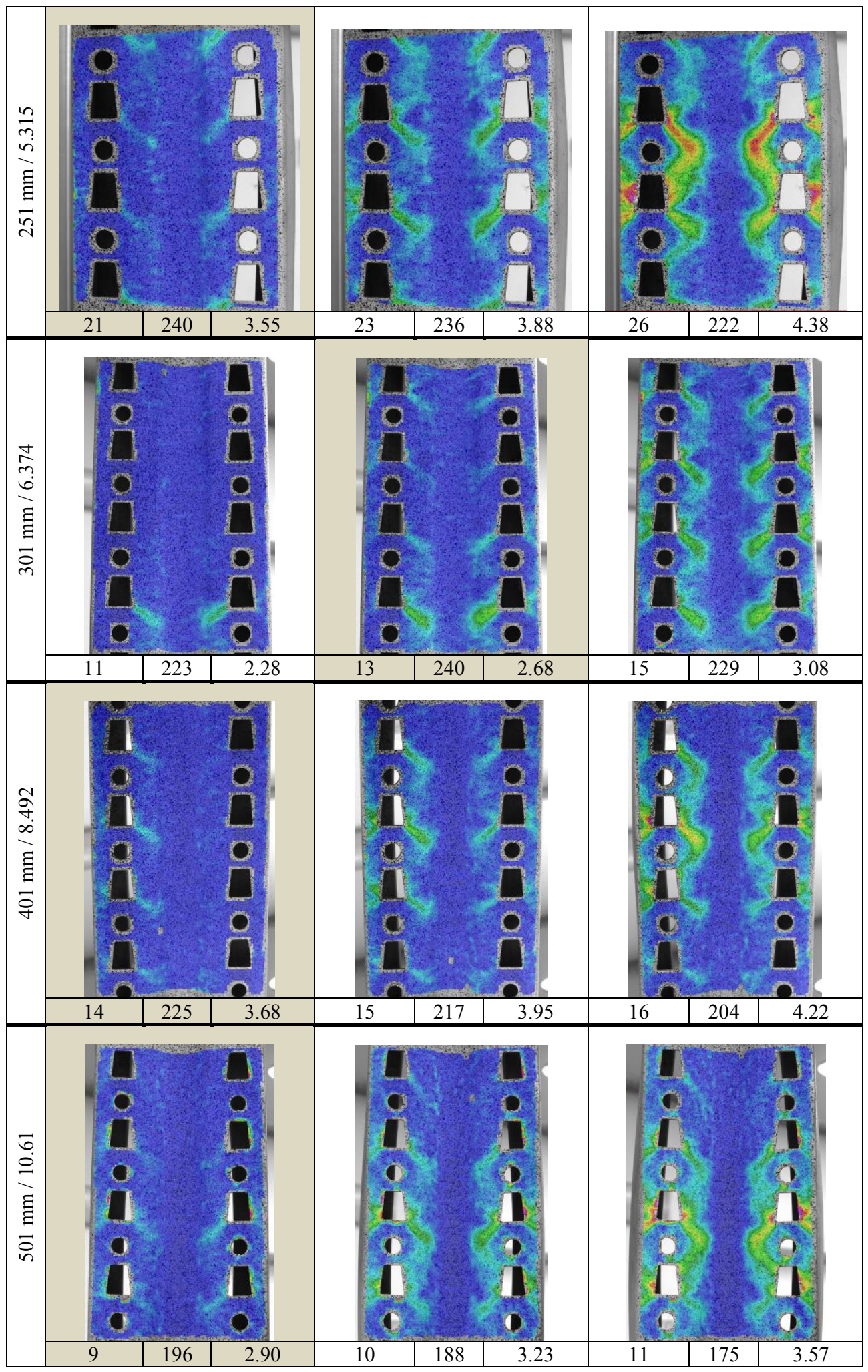




\section{Conclusions}

Tested elements in general are used as a structural elements for storage systems for which compression mode is dominant, so the proper understanding of the element behaviour in post-critical stage is essential for system safety estimation. For the chosen slenderness range of the thin-walled bars, tested elements have to be treated as the perforated shell elements under compression (the shell stability problem). In all cases the deformation mode for subsequent and final configurations are similar. The registered critical forces are decreasing with increasing slenderness, what is the trivial observation, while the tendency can't be properly estimated using solutions of bar's stability elasto-plastic formulation (compare [2,3]). For all cases aside from the shortest one the sample's local failure starts from the sharpest edge of the trapezoidal perforation. In some cases, for average axial strain close to ten percent, the defragmentation of element will occur, see Fig. 6.

Experimental test results on perforated thin-walled bars of low slenderness may be used for validation of numerical models (for example finite element models). These validations may be carried out for checking shell modelling (implementation of the shell theory in FEM), constitutive model verification. In case of constitutive modelling of structural steel of presented examples may be used especially for validation of large deformation plasticity theory like used in [14].

\section{References}

1. J.B. Obrębski, Thin-walled elastic bars (WUT Publishing House, 1991)

2. Ł. Kowalewski, A. Piotrowski, M. Gajewski, S. Jemioło, Monograph from Scientific Conference of IASS Polish Chapters, XXII LSCE 2016, edited by L. Małyszko and R. Tarczewski, 27-30 (UWM Publishing House, 2016)

3. A. Piotrowski, Ł. Kowalewski, R. Szczerba, M. Gajewski, S. Jemioło, MATEC Web of Conferences, 86, 01021 (2016)

4. ARAMIS v6 User Manual, GOM mbH, Mittelweg 7-8 D-38106 Braunschweig (2008)

5. M.A. Sutton, J.J. Orteu, H.W. Schreier, Image correlation for shape, motion and deformation measurements - basic concepts, theory and applications (Springer 2009)

6. W. Głodkowska, J. Domski, M. Staszewski, M. Lehmann, M. Ziarkiewicz, Materiały Budowlane, 5, 89-90 (2017)

7. P. Ziółkowski, Proceedings of TheIRES $8^{\text {th }}$ International Conference, London, 22-26 (2015)

8. C. Ajdukiewicz, M. Gajewski, R. Winzer, S. Jemioło, Lightweight structures in civil engineering, contemporary problems. Monograph from Scientific Conference of IASS Polish Chapters, XIX LSCE 2013, edited by J. B. Obrębski and L. Małyszko, 23-29, (Micro-Publisher-Consultant-Project Jan B. Obrębski, 2013).

9. C. Ajdukiewicz, M. Gajewski, P. Mossakowski, Logistyka, 6, 27-34 (2010)

10. L. Małyszko, A. Rutkiewicz, MATEC Web of Conferences, 117, 00113, (2017)

11. M. Gajewski, Ł. Kowalewski, Materials Testing, 58, 10, 818-825 (2016)

12. Ł. Krawczyk, M. Gołdyn, T. Urban, Journal of Civil Engineering, Environment and Architecture, 64, 259-270 (2017)

13. A. Janowski, W. Kamiński, K. Makowska, J. Szulwic, K. Wilde, 15th International Multidisciplinary Scientific Geoconference, SGEM 2015, Albena, (2015)

14. M. Gajewski, C. Ajdukiewicz, A. Piotrowski, Solid State Phenomena, Trans Tech Publications 240, 61-66, (2015) 